
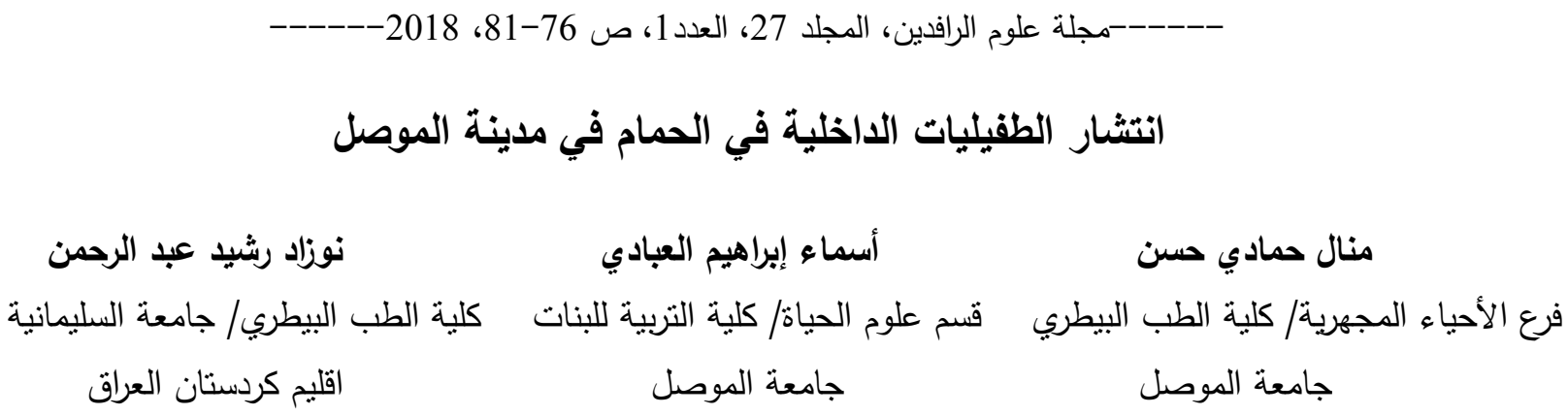

$$
\text { (أستلم 2013/ } 11 \text { (2014/3/ قُبل 20 }
$$

\begin{abstract}
الملخص
تضمنت هذه الدراسة التحري عن الطفيليات الداخلية في 65 طيرا" من الحمام البري Columbi livia تم الحصول عليها من مناطق مختلفة من مدينة الموصل، في الفترة من شهر أيلول 2007 ولغاية شهر كانون الاول 2008 وكانت نسبة الإصـابة

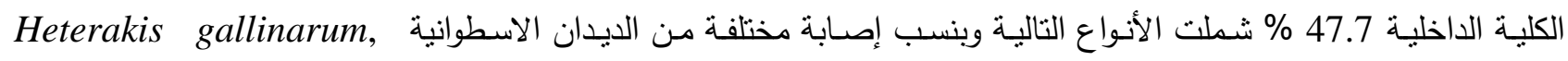
Ascaridia columae
\end{abstract} Haemoproteus بينما الاوالي الدموية والنسيجية فقد شملت Eimeria columbae, Cryptosporidium baileyi المعندية وكان نمط الإصابة columbae, Plasmodium gallinacium, Leucocytozoon marchouxi, Sarcocystis spp.

المختلفة لثلاثة انواع فاكثر هي الاعلى حيث بلغت 41.9٪.

الكلمات الدالة : الطفليات الداخلية، الاوالي الدموية والنسيجية، الحمام.

\title{
A Study of Endoparasites of Pigeons in Mosul City
}

Manal H. Hasan*

Department of Microbiology

College of Veterinary Medicine

University of Mosul
Asmaa E. Al Abbadi

Department of Biology

College of Education Girls

University of Mosul
Nawzad R. Abdul Ruhman

College of Veterinary Medicine

University of Sulamania

District of Kurdstan

*E-mail: manalhimmadi@yahoo.com

\section{ABSTRACT}

The study was conducted to detect the internal parasites in 65 pigeons (Columbi livia) obtained from different regions in Mosul City, from September 2007 to December 2008. The total rate of infection was $47.7 \%$. These include different percentage of infection with Nematodes (Heterakis gallinarum, Ascaridia columbae) from Cestodes (Raillietina tetragona,R.echinobothridium).

The intestinal protozoa were (Eimeria columbae, Cryptosporidium baileyi). While tissue and blood protozoa include (Haemoproteus columbae, Plasmodium gallinacium, Leucocytozoon marchouxi, Sarcocystis spp.).

Mixed infection with three or more different species was the highest with the percentage of $41.9 \%$.

Keywords: Endoparosites, Blood and tissue protozoa, Pigeons. 


\section{المقدمة}

يتعرض الحمام بصورة عامة الى انواع مختلفة من الطفيليات التي تؤدي الى ظهور أعراض الخمول والاسهال وفقر الدم وانخفاض كبير في إنتاج البيض وكمية اللحوم وربما تكون هذه الطفيليات مهلكة للطيور (Ibrahim et al., 1995). اضافة الى لى ماله من تأثير على صحة الإنسان من خلال استتشاق براز الطيور الملوثة وخاصة بالنسبة للأطباء البيطريين ومربي الطيور

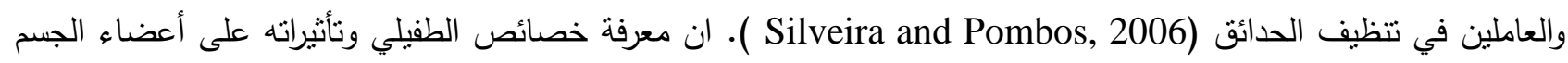

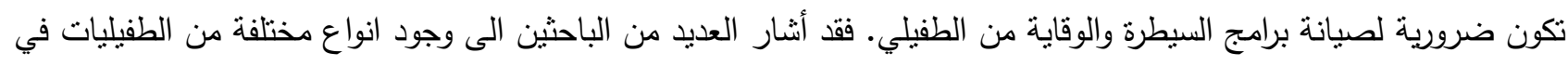

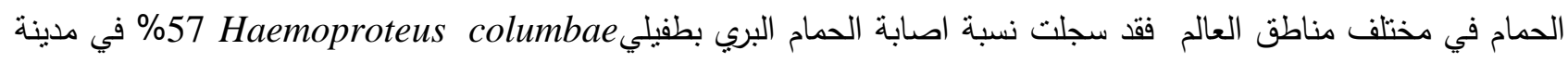
انقرة من قبل (Gicik and Arslan, 2001). وفي البرازيل كانت نسبه اصابة الحمام بطفيليات المعدة والامعاء2074.14) (Marques et al., 2007) مختلفة من الديدان الاسطوانية Capillaria obsignata, Hadjelia truncata, Ascaridia columbae بنسبة إصابة

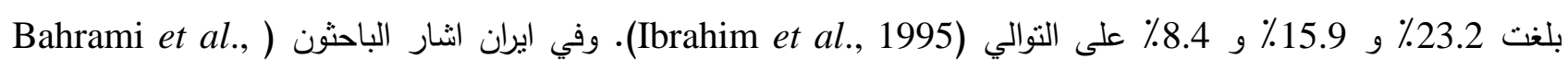

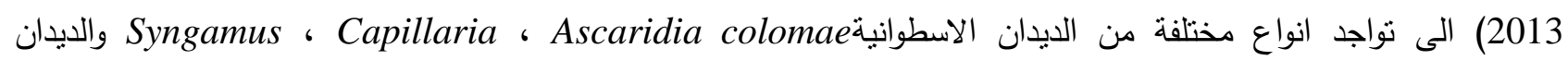
الثريطية .Raillietina spp واكياس بيض الاوالي وبنسب مختلفة في براز الحمام.

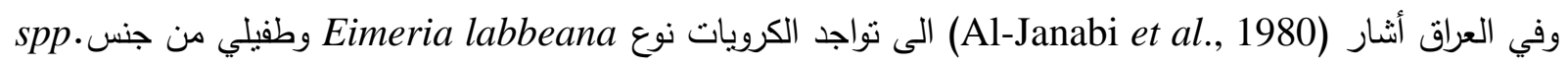

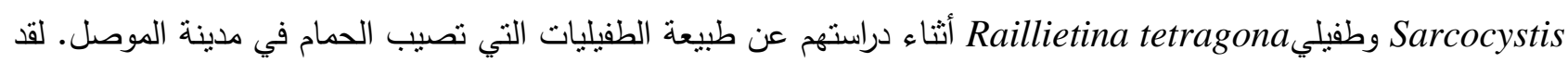
ارتأينا القيام بهذه الدراسة التي كان الهدف منها هو إعطاء صورة واضحة وشاملة لمدى انتشار الطفيليات الداخلية في الحمام البري في مدنية الموصل ودور هذه الطيور في نقل الطفيليات الى الطيور الداجنة ومالها من تأثير في صناعة الدواجن.

\section{المواد وطرائق العمل}

تم في هذه الدراسة التحري عن الطفيليات الداخلية في 65 طير من الحمام البري التي تم الحصول عليها من مناطق مختلفة من مدينة الموصل، العراق، في المدة من شهر أيلول 2007 لغاية شهر كانون الاول 2008 وبعد ذبح الطيور نم أجراء الفحوصات الآتية:

1 - فحص الدم : تم عمل مسحات دموية خفيفة وصبغها بصبغة كيمزا للكثف عن الطفيليات الدموية.

2- فحص البراز ومحتويات الامعاء: اتبعت الطرائق التالية :

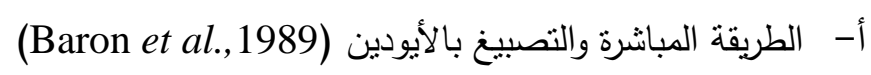

ب- طريقة الطفو (Coles, 1986; Urquhart et al., 2003) : للكثف عن بيوض وأكياس بيض طفيليات الأمعاء.

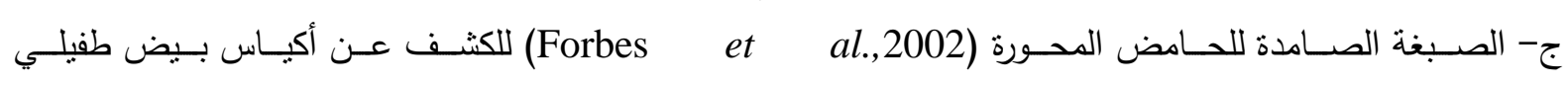

.Cryptosporidium

3- فحص الأنسجة: تـم اخـ 2 غم مـن الأنسجة العضـلية للفخذ والصـدر للحمـام وتم فحصـها بطريقـة منظــار الثـعريات

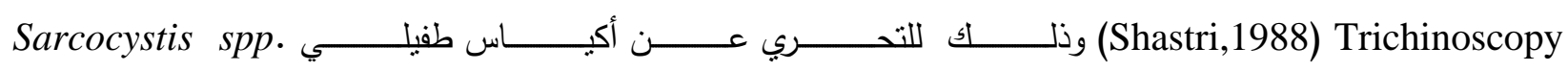

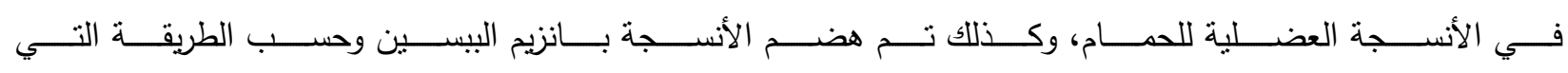
ذ كرهـا (Collins Gardinar et al., 1988 ; Soulsby,1986; Levine, 1985) المجرية. وتم تتخيص جميع الطفيليات بالاعنماد على 


\section{النتائج والمناقشة}

أشثارت نتائج هذه الدراسة الى ان الحمام البري معرض للإصابة بمختلف انواع الطفيليات (الاوالي المعوية والدموية والنسجية

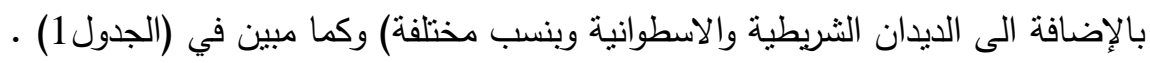

الجدول 1: يبين أنواع الطفيليات وموقع الاصابة في الحمام

\begin{tabular}{|c|c|c|}
\hline موقع الاصابة & أنواع الطفيليات & صنف لطفيليات \\
\hline الامعاء الاقيقة & $\begin{array}{l}\text { Ascaridia columbae } \\
\text { Heterakis gallinarum }\end{array}$ & $\begin{array}{l}\text { الديدان الاسطوانية } \\
\text { Nematods }\end{array}$ \\
\hline الامعاء الدقيقة & $\begin{array}{l}\text { Raillietina tetragona } \\
R . \text { echinobothridium }\end{array}$ & $\begin{array}{l}\text { الديدان الشريطية } \\
\text { Cestods }\end{array}$ \\
\hline الامعاء الاء الدقيقة & $\begin{array}{c}\text { Eimeria columbae } \\
\text { Cryptosporidium baileyi }\end{array}$ & \multirow[t]{5}{*}{$\begin{array}{l}\text { الاوالي الحبوانية } \\
\text { Protozoa }\end{array}$} \\
\hline 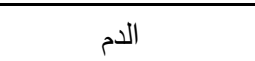 & Haemoproteus columbae & \\
\hline 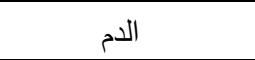 & Plasmodium gallinacium & \\
\hline 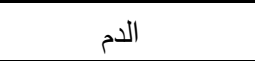 & Leucocytozoon marchouxi & \\
\hline عضلات الفخد والصدر & Sarcocystis spp. & \\
\hline
\end{tabular}

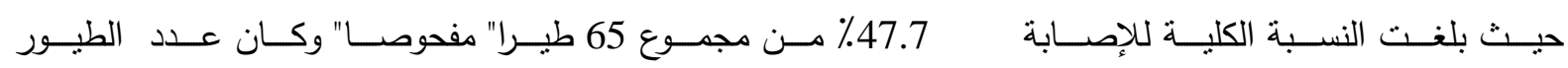

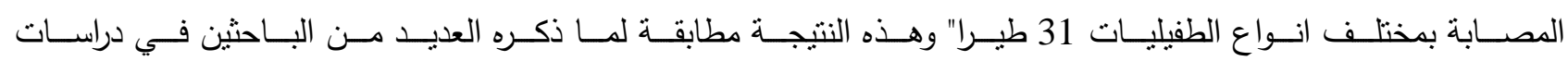

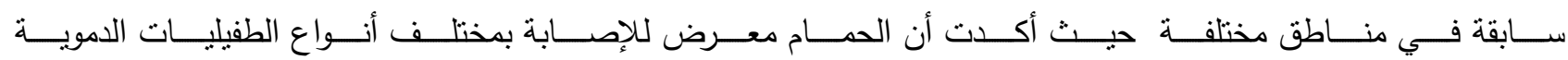

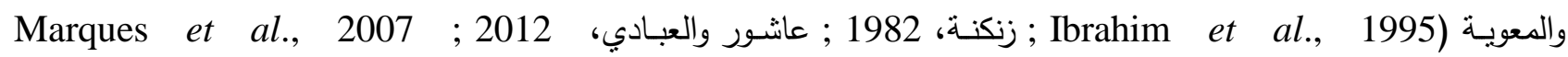

.(Al- Bayati, 2011;

وفي هذه الدراسة سجلت اعلى نسبة للإصابة بطفيلي E. columbae اذ بلغت 23.08٪ من بين مختلف انواع الطفيليات المدروسة، حيث سجل باحثون آخرون نسبة اصابة 19٪ بنثاء دراستهم عن الإصابات الطفيلية في الحمام في مدنية الموصل (عاشور والعبادي، 2012). وفي بغداد سجل الباحثان (Mahdi and Al-Rubaie, 2013) نسبة اصابة

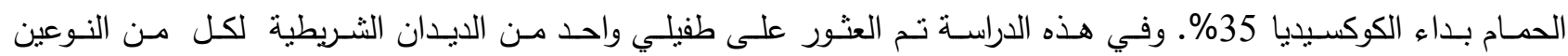
R.echinobothrida، Raillietina tetragona الجدول 2: يبين إعداد و نسب الاصابة بمختلف انواع الطفيليات في الحمام المفحوص

\begin{tabular}{|c|c|c|}
\hline \% & إعداد الحمام المصاب| \\
\hline 4.62 & 3 & Ascaridia columbae \\
\hline 6.15 & 4 & Heterakis gallinarum \\
\hline 1.54 & 1 & Raillietina tetragona \\
\hline 1.54 & 1 & R. echinobothridium \\
\hline 23.08 & 15 & Eimeria columbae \\
\hline 7.69 & 5 & Cryptosporidium baileyi \\
\hline 1.54 & 1 & Haemoproteus columbae \\
\hline 4.62 & 3 & Plasmodium gallinacium \\
\hline 3.08 & 2 & Sarcocystis spp . \\
\hline 3.08 & 2 & Leucocytozoon marchouxi \\
\hline
\end{tabular}




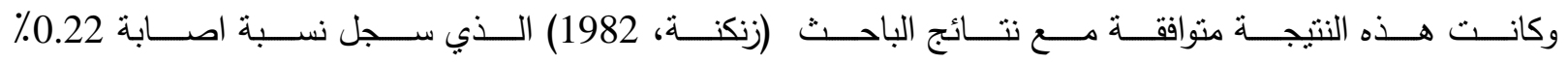

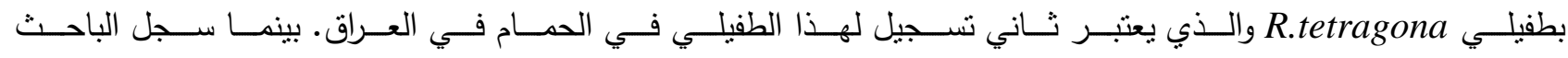
نسبة اصابة الحمام بطفيلي Radfar et al., 2011) النسب الى مدى توفر المضائف الوسطية للايدان في الأماكن التي يتخذى فيها الحمام.

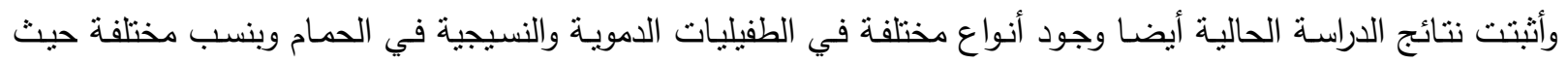
Sarcocystis Leucocytozoon marchouxi, Haemoproteus columbae, Plasmodium gallinacium, كانت spp, وبلغت نسبة الاصـابة 1.54 ٪ ، 62. مقارنة مع ما سجله الباحث (الثعيبي، 2008) أثناء دراسته على الطفيليات الدموية في الحمام في ددينة الرمادي، حيث سجل نسـبة اصـابة الحمـام بالطفيليـات الدمويـة 32.14٪، وبلغـت نسـبة الإصـابة بطفيلـي 28.75 Plasmodium، وطفيلي 10.7 Haemoproteus Radfar et al., 2011) \% (2.05 Haemoproteus columbae الحمام المحلي بالطفيليات الدموية 28.5 ٪ في مدنية البصرة. وقد يعود السبب في هذا التفاوت في نسب الإصابة في المناطق

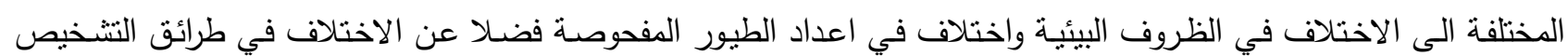
المستخدمة.

إن الإصـابة بالطفيليـات الامويـة والنسـيجية في الحمـام في مدنيـة الموصـل قد درست مـن قبـل العديد مـن البـاحثين (Al-Janabi et al., 1980) ؛ زنكنة، 1982 ؛ عاشور والعبادي، 2012) ولم ينطرق الباحثون في دراستهم الى تواجد طفيلي Leucocytozoon marchouxi

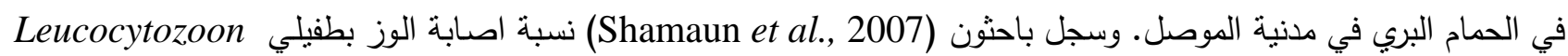

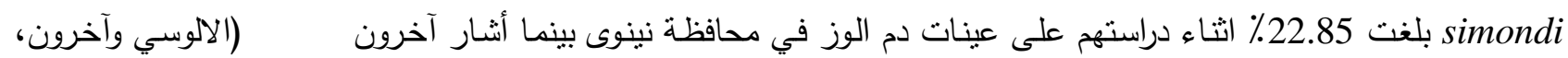
1994) إلى تواجد طفيلي Leucocytozoon smithi بنسبة 14\% في مسحات دم الديك الرومي في مدنية الموصل، وهذا يعود الى توفر المضيف الوسطي الناقل بهذا الطفيلي وهو الذباب الاسود blackflies الذى يعود الى عائلة Simuliidae في بيوت الطيور والدجاج المنزلي المربى في الحدائق (Soulsby, 1986 ).

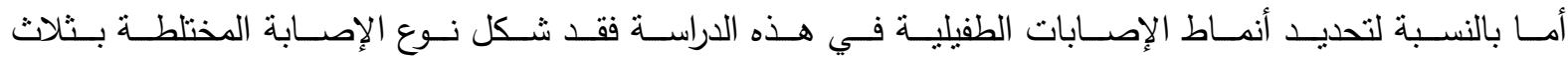

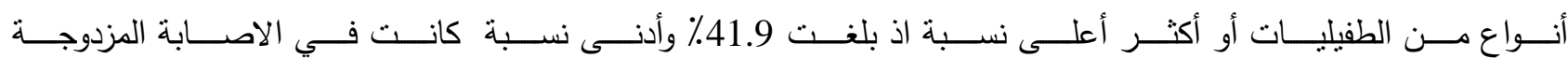
بلغت 25.8\% (الجدول 3).

الجدول 3 : يبين أنماط الإصابات الطقيلية في الحمام

\begin{tabular}{|c|c|c|}
\hline نسبة الاصابة \% & أعداد الحمام المصاب & نمط الإصابة \\
\hline 32.3 & 10 & الفردية \\
\hline 25.8 & 8 & المزدوجة \\
\hline 41.9 & 13 & المختلطة \\
\hline 47.7 & 31 & المجموع \\
\hline
\end{tabular}

ونستتتج من هذه الدراسة ان الحمام البري في مدينة الموصل يصاب بأنواع مختلفة من الطفيليات الداخلية وهذا لهه أهمية كبيرة في نقل الطفيليات الى الطيور الداجنة الأخرى. 


$$
\begin{aligned}
& \text { الإدريسي، سهير رياض احمد (2010). تسجيل جديد لبعض الشريطيات وطفيليات الدم من الحمام المحلي في مدينة البصرة. }
\end{aligned}
$$

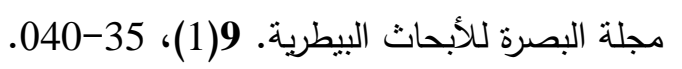

$$
\begin{aligned}
& \text { الالوسي، توفيق إبراهيم؛ دواد، محسن سعدون؛ البياتي، محمد علي (1994). دراسـة الطفيليات الداخلية في الديك الرومي في }
\end{aligned}
$$

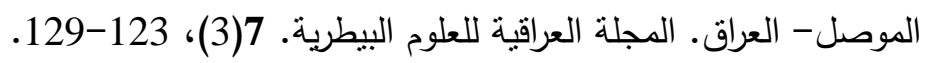

$$
\begin{aligned}
& \text { زنكنة، فوزي محمد (1982). دراسة حول طفيليات الحمام الاليف في محافظة نينوى وبعض مناطق محافظتي أربيل ودهوك. } \\
& \text { رسالة ماجستير ، كلية العلوم، جامعة الموصل. } \\
& \text { الثعيبي، مهند محمد (2008). دراسة انتشار الطفيليات الدموية في انواع مختلفة من الطيور في مدنية الرمادي. مجلة الانبار }
\end{aligned}
$$

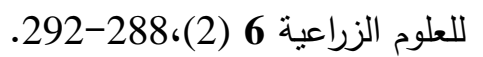

$$
\begin{aligned}
& \text { عاشور ، أزهار عباس؛ العبادي، أسماء إبراهيم (2012). بيركسدة الدهن وعلاقتها بالإصـابة الطفيلية في الطيور ـ وقائع المؤثز } \\
& \text { العلمي السادس، كلية الطب البيطري، جامعة الموصل. } 6 \text { (3). } \\
& \text { المصادر الأجنبية }
\end{aligned}
$$

Al-Bayati, N.Y. (2011). Astudy on pigeons (Columbi livia) Cestodes infection in Diyala province. Diyala Agri. Sci. J., 3(2),1-12.

Al-Janabi, B.M.; Al.sadi, H.I.; Hayatee, Z.G. (1980). Some parasites of pigeons From Mosul province. J. Coll. Vet. M ed. Mosul 1(2),15-26.

Bahrami, A.M.; Hosseini, E.; Razmjo, M. (2013). Important parasite in Pigeon, its Hematological parameter and pathology of Intestine. World Appl . Sci . J., 21(9),1361-1365.

Baron, E.J.; Schenone, C.; Tanenbaum, B. (1989). Comparison of three methods for detection of Cryptosporidium oocysts in alow prevalence population. J. Clin. Microbiol. 27(1),223-224.

Coles, E.H.(1986). Lea Kocytes. In: Veterinary Clinical pathology.4 th edition. W.B.Saunders Company Philadelphia, London, Toronto, Mexico City, Rio de Janeiro, Sydney, Tokyo, llong Kong, pp. 43-64.

Collins, G.H., Charleston, W.A.G.; Wiens, B.G. (1980). Studies on Sarcocystis species VI: Comparisons of three methods for the detection of Sarcoycystis species in muscles. N.Z .Vet. J., 28, 173.

Forbes, B.A.; Sahm, D.F.; Weissfeld, A.S. (2002). Diagnostic Microbiology.11ed Mosby, Inc. pp.705.

Gardinar, C.H.; Fayer, R.; Dubey, J.P.(1988). An atlas of protozoan parasites in animal tissues. U.S., Agriculture Handbook, Washington, pp. 72,73.

Gicik, Y.; Arslan, O. (2001). Blood parasites of wild pigeons in Ankara district. Turk. J. Vet. Anim. Sic., 25, 169-172.

Ibrahim, A.I.; Hassann, H.H.; Aly, S.E.M.; Abdellaal, A.A. (1995). Astudy on some parasitic affections in domestic pigeons in Ismailia province. Assiut vet. Med J. vol. 34(67), 153 161.

Levine, N.D. (1985). Veterinary Protozoology Iowa State University press.Ames. pp. 265-287.

Mahdii, E.F.; Al-Rubaie, H.M.A. (2013). Study the prevalence of pigeon coccidiosis in Baghdad City. Iraq. J. Vet. Med. 37(1), 106-108.

Marques, S.M.T.; Quadros, R.M.; Silva, C.J.; Baldo, M. (2007). Parasites of pigeons (Columba livia) in Urban areas of Lages, Southern Brazil. Parasit of Latinoam 62, 183-187.

Radfar, M.H.; Fathi, S.; Asi, E.N.; Dehaghi, M.M.; Seghinsara, H.R. (2011). A survey of parasites of domestic pigeons (Columba livia domestica) in south Khorasan, Iran Vet. Res. 4(1),1823. 
Shamanun, A.A.; Al-Taee, A.M.; Hasan, M.H. (2007). Parasitological and histopathological studies of the natural infection with Leucocytozoon simondi in geese in Ninevah governorate. Iraq $J$. Vet. Sci., (21), 37-44.

Shastri, U.V. (1988). Sarcocystis infection in goats in Maharashtra. J .Vet Parasitol., 2,117-119.

Silveira, T.L.; Pombos. Simbolos dapaz ouamea caasaude publica? (2006) Available at http:// www.geocities. Com /Rain foest /Jungle / 9625/numerotreze 4 . htm.

Sloss, M.W. (1994). Veterinary Clinical Parasitolgy 6th ed. Iowa State University Press, Ames. pp.80, 110-113.

Soulsby, E.J.L. (1986). "Helminths, Arthropods and Protozoa of Domesticated Animals". $7^{\text {th }}$ ed., Bailliere Tindall, London, pp.100-162-165.

Urquhart, G.M., Armour, J.; Duncan, J.L.; Duun, A.M.; Jennings, F.W. (2003). "Veterinary Parasitology". $2^{\text {nd }}$ ed. Black well Science Ltd; 276 p. 